\title{
Pharmacology of Cardio-Oncology: Chronotropic and Lusitropic Effects of B-Type Natriuretic Peptide in Cancer Patients with Early Diastolic Dysfunction Induced by Anthracycline or Nonanthracycline Chemotherapy
}

\author{
Pierantonio Menna, Vito Calabrese, Grazia Armento, Ombretta Annibali, Carlo Greco, \\ Emanuela Salvatorelli, Francesco Marchesi, Giorgio Reggiardo, and Giorgio Minotti
}

Units of Drug Sciences (P.M., E.S., G.M.), Cardiovascular Sciences (V.C.), Oncology (G.A.), Hematology (O.A.), and Radiation Oncology (C.G.), Department of Medicine and Center for Integrated Research, University Campus Bio-Medico, Rome, Italy; Hematology and Stem Cell Transplant Unit, IRCCS Regina Elena National Cancer Institute, Rome, Italy, (F.M.); and Mediservice S.r.I., Agrate Brianza, Monza, Italy (G.R.)

Received March 22, 2018; accepted April 30, 2018

\begin{abstract}
B-type natriuretic peptide (BNP) is widely used as a diagnostic marker of systolic dysfunction. We previously conducted a clinical study in which anthracycline or nonanthracycline chemotherapy did not cause systolic dysfunction in cancer patients; however, some patients showed asymptomatic alterations in diastolic relaxation, whereas others showed persistent elevations of BNP, measured as prohormone BNP amino-terminal fragment. Here we describe post hoc pharmacologic analyses showing that: 1) impaired relaxation and persistent elevations of BNP were mutually exclusive manifestations of diastolic dysfunction; 2) in some patients, BNP elevations were induced by an early compromise of myocardial relaxation; 3) BNP elevations then halted further deterioration of relaxation in a concentration-dependent manner; and 4) high BNP increased heart rate (HR). BNP elevations therefore caused positive lusitropy and chronotropism, which might be
\end{abstract}

explained by activation of natriuretic receptor-associated guanylyl cyclase and production of cGMP in ventricular myocytes and sinoatrial node, respectively. BNP levels also influenced responses to a lusitropic drug, ranolazine, that was given to treat diastolic dysfunction. For patients with impaired relaxation and normal or only transiently high levels of BNP, ranolazine improved myocardial relaxation without inducing chronotropic effects. For patients in whom relaxation abnormalities were corrected by persistently high BNP levels, ranolazine substituted for BNP and decreased HR by diminishing BNP levels. These findings describe a pharmacologic scenario in which cancer drugs cause an early diastolic dysfunction that in some patients is both heralded and modulated by BNP elevations. Patients showing BNP elevations should therefore receive the adequate pharmacologic treatment of correcting diastolic dysfunction and tachycardia.

\section{Introduction}

B-type natriuretic peptide (BNP) is widely used as a diagnostic marker of cardiac dysfunction, primarily but not exclusively in the settings of acute and chronic heart failure (HF). Under conditions of hemodynamic stress, such as when the ventricles are dilated, hypertrophic, or exposed to abnormal wall tension, cardiomyocytes secrete a prohormone BNP that is cleaved by circulating endoproteases to release active BNP (Daniels and Maisel, 2007; Braunwald, 2008). $\mathrm{BNP}$ then causes arterial vasodilation, stimulates diuresis and natriuresis, and mitigates the activities of renin-angiotensin

This study was promoted by Menarini International Operations Luxembourg S.A. and was registered at the European Clinical Trials Database (EUDRACT 2009-016930-29)

https://doi.org/10.1124/jpet.118.249235. system and sympathetic nervous system. Hemodynamic actions of BNP therefore play an intuitively beneficial effect for patients affected by HF (Braunwald, 2008).

Circulating endoproteases also release the amino-terminal fragment of prohormone BNP (Nt-proBNP). This peptide is hemodynamically inactive but shows a significantly longer half-life compared with active BNP (120 minutes vs. 20 minutes) (Weber and Hamm, 2006). Inasmuch Nt-proBNP is formed in (1:1) ratio to BNP, one may use Nt-proBNP for improving BNP detection and prognostic value in cardiovascular disease (Masson et al., 2006; Omland et al., 2007).

Many cancer drugs can cause cardiotoxicity. Anthracyclines induce dilative cardiomyopathy and HF (Minotti et al., 2004; Vejpongsa and Yeh, 2014). Nonanthracycline drugs, like antimetabolites or alkylators or tubuline-active agents, may cause cardiac events by inducing microvasculature dysfunction (Menna et al., 2008). BNP and Nt-proBNP have therefore been

ABBREVIATIONS: BMI, body mass index; BNP, B-type natriuretic peptide; DBP, diastolic blood pressure; DT, mean deceleration time of early filling velocity; $E / A$, mean ratio of peak early filling ( $E$ wave) to late diastolic filling (A wave); $E C G$, electrocardiogram; $H b$, hemoglobin; $H F$, heart failure; HR, heart rate; LVEF, left ventricular ejection fraction; Nt-proBNP, amino-terminal fragment of B-type natriuretic peptide pro-hormone; PKG, protein kinase G; SBP, systolic blood pressure. 
considered potential biomarkers of cardiac dysfunction also in oncologic settings, but their role in the management of cancer patients is much less defined compared with management for the general population (Zamorano et al., 2016).

When monitoring cancer patients for whom BNP or Nt-proBNP was used primarily for detecting or predicting the occurrence of systolic dysfunction, conflicting results were obtained across different studies, which was attributed to differences in chemotherapy regimens (Romano et al., 2011). Moreover, hemodynamic effects of BNP elevations were not explored for patients without systolic dysfunction, which leaves unanswered numerous questions about BNP. The pathophysiologic foundations of cardiotoxicity are in fact laid during chemotherapy, but systolic dysfunction may take longer to occur, sometimes months or years after cancer diagnosis and treatment (Minotti et al., 2010; Menna and Salvatorelli, 2017). The current thinking is that systolic function declines when overt cardiac damage has already occurred (Ewer and Lenihan, 2008); if BNP elevations were detected during or shortly after chemotherapy in patients with a preserved systolic dysfunction, one would have an opportunity to intercept cardiotoxicity in its early stages and to characterize the role of $\mathrm{BNP}$ in these settings.

Early asymptomatic diastolic dysfunction is suspected to precede systolic dysfunction and other clinical manifestations of cardiotoxicity (Carver et al., 2007; Minotti et al., 2010). BNP elevations have also been considered to denote diastolic rather than systolic dysfunction (Lukowicz et al., 2005). We recently completed a pilot multicenter study of early asymptomatic diastolic dysfunction in patients treated by anthracyclinebased or nonanthracycline chemotherapy. In that study, both echocardiographic imaging and Nt-proBNP elevations were used to detect diastolic dysfunction 1 week after the last chemotherapy dose. We found that echocardiographic indices of impaired diastolic relaxation and Nt-proBNP elevations occurred in 28 of 80 patients, but the two events were mutually exclusive, with only one patient developing both impaired relaxation and out-of-range Nt-proBNP. Remarkably, all patients showed a preserved systolic function. We therefore speculated that BNP elevations, measured as Nt-proBNP, caused a positive lusitropic effect that prevented the occurrence of impaired diastolic relaxation (Calabrese et al., 2018).

In the same study, Nt-proBNP was measured for investigational purposes, also before each chemotherapy cycle. Here the serial measurements of Nt-proBNP were analyzed to define the pattern or patterns of BNP elevations and to characterize cause-and-effect relations between such patterns and the presence or absence of diastolic dysfunction at the end of chemotherapy. We provide evidence to support that BNP elevations, measured as Nt-proBNP, can in fact induce a lusitropic effect that mitigates diastolic dysfunction. We also show that BNP induces a positive chronotropic effect. These findings are incorporated in a pharmacologic framework where anthracyclines or nonanthracycline drugs cause cardiotoxicity, and BNP serves not only as a diagnostic marker but also as an endogenous modifier of cardiotoxicity.

\section{Experimental Procedures}

Patients. All data derived from a pilot prospective, multicenter, real-life study of early cardiotoxicity induced by standard-dose anthracycline-based or nonanthracycline chemotherapy (Calabrese et al., 2018). Patient demographic, oncologic, and cardiovascular characteristics at baseline (T0) were 18-70 years of age; Eastern Cooperative Oncology Group performance status of 0 to 1 ; eligibility for anthracycline-based adjuvant therapy of breast cancer or frontline therapy of newly diagnosed nonHodgkin lymphoma, nonanthracycline (fluoropyrimidine-platinum) adjuvant therapy of colorectal cancer; normal electrocardiogram (ECG; left ventricular ejection fraction $(\mathrm{LVEF}) \geq 50 \%$; normal diastolic function at two-dimensional echocardiography; normal systolic and diastolic blood pressure (SBP and DBP, respectively); normal levels of Nt-proBNP; and absence of any cardiovascular or metabolic disease requiring pharmacologic treatment.

Eighty patients were evaluated by echocardiography and Nt-proBNP at $\mathrm{T} 0$ and 1 week after chemotherapy (T1). Intertreatment blood samples for Nt-proBNP assays were obtained before each chemotherapy cycle from a subgroup of 67 patients. Demographic and oncologic characteristics of the study subgroup were identical to the complete cohort of 80 patients (source population); both groups showed a prevalence of women treated by anthracyclines for breast cancer. In most cases, women with breast cancer received four cycles of anthracycline-cyclophosphamide $(60 \mathrm{mg}$ of doxorubicin $/ \mathrm{m}^{2}$ or $90 \mathrm{mg}$ of epirubicin $/ \mathrm{m}^{2}$ every 3 weeks), followed by four cycles of taxane (100 mg of docetaxel $/ \mathrm{m}^{2}$ every 3 weeks). Patients with non-Hodgkin lymphoma received six cycles of rituximab/cyclophosphamide/doxorubicin/vincristine/prednisone $(50 \mathrm{mg}$ of doxorubi$\mathrm{cin} / \mathrm{m}^{2}$ every 3 weeks). The study subgroup and the source population were also balanced for the incidence of impaired diastolic relaxation (grade 1 diastolic dysfunction at echocardiography) and/or out-of-range Nt-proBNP at T1 (Table 1). The study subgroup was therefore fully representative of the source population.

The study was compliant with the Declaration of Helsinki and approved by the institutional review board of each participating center. Written informed consent was obtained from all patients.

Nt-proBNP Assay. Nt-proBNP was measured in heparin-lithium plasma by Siemens immune-chemiluminescence assay for Dimension Vista System (Luminescent Oxygen Channeling Immunoassay technology, Erlangen, Germany), precisely as described (Calabrese et al., 2018). The assay was linear over 5-35.000 pg/ml (Calabrese et al., 2018), and the limit of normality was set at $125 \mathrm{pg} / \mathrm{ml}$ per manufacturer's recommendation for patients 18-70 years of age (Siemens Technical Note, 2012). All assays were performed at the Clinical Pharmacology Unit of University Campus Bio-Medico of Rome. Where indicated, some patients diagnosed at T0 had Nt-proBNP $>125 \mathrm{pg} / \mathrm{ml}$ that was caused by emotional distress resulting from their cancer diagnosis (Politi et al., 2007). These patients recovered from their distress and showed normalization of Nt-proBNP over the first two or three cycles of chemotherapy; they were therefore included in the study and evaluated for BNP at T1. A few other patients diagnosed at T1 with Nt-proBNP > $125 \mathrm{pg} / \mathrm{ml}$ caused by noncardiac events like, for example, fever, were considered normal by the investigators.

Other Conditions. Systolic function was determined by twodimensional echocardiographic measurements of LVEF, as described (Calabrese et al., 2018). HR was determined by the R-R interval at 12-lead ECG. Diastolic function was evaluated by the mean ratio of peak early filling ( $\mathrm{E}$ wave) to late diastolic filling (A wave), E/A ratio, and by the mean deceleration time of early filling velocity (DT), as also described (Calabrese et al., 2018). Only grade 1 diastolic dysfunction (impaired relaxation) was detected (E/A decrements and concomitant DT prolongation). Abnormalities of Doppler imaging of mitral annulus were not observed, which was anticipated for patients without HF (Previtali et al., 2012; Calabrese et al., 2018). To avoid interobserver variability, each center identified a study-dedicated operator. At the end of the study, echocardiograms were reviewed by an independent expert for completeness, quality, and consistency of imaging sources. Where indicated, E/A and DT were normalized to age-related ranges by the formula in eq. 1:

$$
\mathrm{E} / \mathrm{A}(\text { or DT })=100 \times[(\text { absolute value-lower limit of range }) / \text { range }]
$$

This normalization was done considering physiologic age-related changes of myocardial relaxation and to permit comparison among 
TABLE 1

Demographic and oncologic characteristics of source population and study subgroup

\begin{tabular}{|c|c|c|c|}
\hline Characteristics & $\begin{array}{l}\text { Source population } \\
\qquad(n=80)\end{array}$ & $\begin{array}{l}\text { Study subgroup } \\
\qquad(n=67)\end{array}$ & $\mathbf{P}$ \\
\hline Age (years, median, range) & $49(28-68)$ & $49(28-68)$ & 0.652 \\
\hline $\begin{array}{l}\text { Gender }(n, \%) \\
\text { male } \\
\text { Female }\end{array}$ & $\begin{array}{l}12(15 \%) \\
68(85 \%)\end{array}$ & $\begin{array}{l}11(16 \%) \\
56(84 \%)\end{array}$ & 0.981 \\
\hline $\begin{array}{l}\text { Oncologic disease }(\mathrm{n}, \%) \\
\text { breast cancer } \\
\text { non Hodgkin lymphoma } \\
\text { colorectal cancer }\end{array}$ & $\begin{array}{l}55(69 \%) \\
17(21 \%) \\
8(10 \%)\end{array}$ & $\begin{array}{l}43(64 \%) \\
17(25 \%) \\
7(11 \%)\end{array}$ & 0.747 \\
\hline $\begin{array}{l}\left.\text { Anthracycline dose }{ }^{\mathrm{c}}\right) \\
\left(\mathrm{mg} / \mathrm{m}^{2}, \text { median, range }\right)\end{array}$ & $240(0-317)$ & $240(0-317)$ & 0.683 \\
\hline $\begin{array}{c}\text { Diastolic events at T1 } \\
\text { Impaired relaxation }{ }^{\mathrm{d})} \\
\text { High Nt-proBNP }^{\mathrm{e})} \\
\text { Impaired relaxation + high Nt-proBNP }\end{array}$ & $\begin{array}{l}13(16 \%) \\
14(18 \%) \\
1(1.3 \%)\end{array}$ & $\begin{array}{l}13(19 \%) \\
12(18 \%) \\
1(1.5 \%)\end{array}$ & 0.829 \\
\hline
\end{tabular}

Data were analyzed by two-tailed Mann-Whitney test, two-tailed square chi test or Fisher's exact test, as appropriate.

${ }^{a}$ Doxorubicin (or epirubicin)/cyclophosphamide followed by docetaxel; epirubicin/cyclophosphamide/docetaxel; 5-fluorouracil/epirubicin/cyclophosphamide, with or without a subsequent docetaxel; rituximab/cyclophosphamide/doxorubicin/vincristine/prednisone (for non-Hodgkin lymphoma).

${ }^{b}$ Folinate/5-fluorouracil/oxaliplatin; capecitabine/oxaliplatin.

${ }^{c}$ Expressed as doxorubicin myelotoxic equivalents.

${ }^{d}$ Grade 1 diastolic dysfunction at echocardiography.

${ }^{e} \mathrm{Nt}$-proBNP $>125 \mathrm{pg} / \mathrm{ml}$.

patients of different ages (Calabrese et al., 2018). Throughout this study, myocardial relaxation was expressed by E/A changes; comparable results were obtained by expressing impaired relaxation as DT prolongation.

Cumulative anthracycline doses were expressed as doxorubicin myelotoxic equivalents (Ewer, 2013). Where indicated, some patients were treated for 5 weeks with ranolazine as recommended by the European Medicines Agency for its approved indication in chronic angina ( $375 \mathrm{mg}$ twice daily for 2 weeks, followed by $500 \mathrm{mg}$ twice daily for 10 days and $750 \mathrm{mg}$ twice daily for 10 additional days) (European Medicines Agency, 2016).

Statistical Analysis. Data are expressed as median with range, or as numbers and percentage, and were analyzed by Kruskal-Wallis one-way analysis of variance with Dunn's post-hoc test, two-tailed Mann-Whitney test, or Wilcoxon matched-pair test, as appropriate. Categorical variables were analyzed by Chi-square test or Fisher's exact test. Differences were considered significant when $P$ value was $<$ 0.05. Linear regression analyses and best-fitting curves of nonlinear regressions were obtained by Prism 5, version 5.01 (GraphPad Software Inc., La Jolla, CA). Other details are reported in the legends for the figures and tables.

\section{Results}

Patterns of Nt-proBNP from To to T1. Nt-proBNP was measured in 67 patients at baseline (T0), before each chemotherapy cycle, and 1 week after the last chemotherapy cycle (T1). At T1, 55 patients were diagnosed with Nt-proBNP below the limit of normality (125 pg/ml) (Fig. 1A); interestingly, however, only 28 of 55 patients showed normal levels of Nt-proBNP also during the course of chemotherapy, and the remaining 27 patients showed transient elevations of Nt-proBNP during chemotherapy. These two subgroups were referred to as "normal" or "transiently high" Nt-proBNP, respectively (Fig. 1, B and C). Twelve other patients showed Nt-proBNP $>125 \mathrm{pg} / \mathrm{ml}$ at T1 (Fig. 1D). In these latter patients, Nt-proBNP began to increase over the second half of chemotherapy, exceeded $125 \mathrm{pg} / \mathrm{ml}$ at $\mathrm{T} 1$, and was significantly greater compared with T0 $(P<0.001)$ or compared with normal or transiently high Nt-proBNP at T1 $(P<0.001)$. This group was referred to as "persistently high" Nt-proBNP (Fig. 1E).

Patients with normal, transiently high, or persistently high Nt-proBNP were balanced for demographic and oncologic characteristics such as tumor type and anthracycline versus nonanthracycline chemotherapy, the only exceptions being that: 1) there were more women in the group with transiently high Nt-proBNP compared with the group with normal Nt-proBNP, and 2) the group with persistently high Nt-proBNP was composed of only women (Table 2). Remarkably, however, women in the three groups were balanced for age $(P=0.712)$ and menopausal status $(P=0.193)$. Patients were balanced also for LVEF, SBP, and DBP, which were normal for all patients (Table 3). Thus, patients with different patterns of Nt-proBNP were similar for factors that are known to influence BNP levels (Braunwald, 2008). 

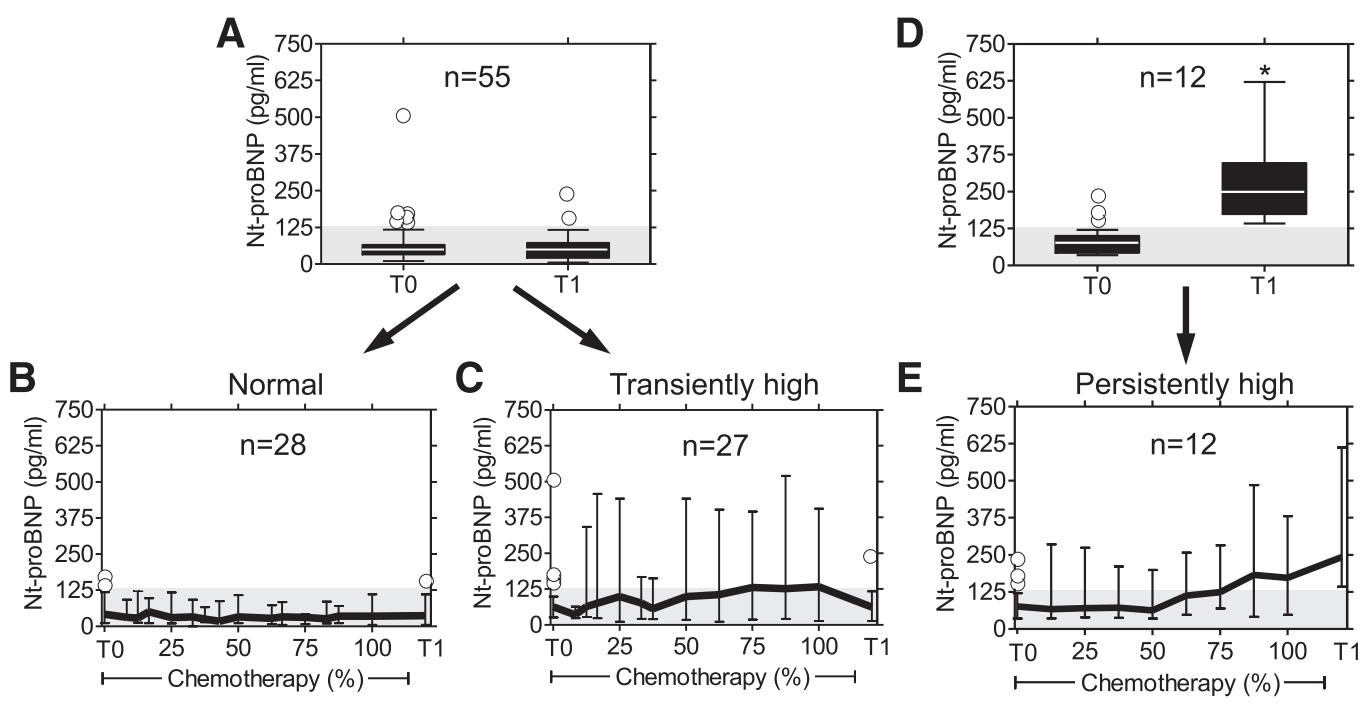

Fig. 1. Patients with normal, transiently high, or persistently high Nt-proBNP. (A) Patients with normal ( $<125 \mathrm{pg} / \mathrm{ml}) \mathrm{Nt}$-proBNP at T1. This group of patients included a subgroup in which Nt-proBNP was normal throughout chemotherapy (B) and a subgroup that showed transient elevations during chemotherapy (C). (D) Patient with high ( $>125 \mathrm{pg} / \mathrm{ml})$ Nt-proBNP at T1 $(* P<0.001$ for Nt-proBNP at T1 vs. T0). In these last patients, Nt-proBNP gradually increased over the second half of chemotherapy (E). Values are shown in whisker plots with medians and ranges (A and D) or medians with ranges (B, C, and E). Shaded areas indicate the range of normality. Chemotherapy was expressed as the percentage of length to permit comparisons among oncologic regimens of different durations. Open symbols denote out-of-range levels that the investigators considered normal according to patients' characteristics at T0 or T1. Outof-range values at T0 normalized over the first two or three cycles of chemotherapy and were therefore included in the analyses.

An inverse correlation has been suggested to occur between body mass index (BMI) and BNP or Nt-proBNP (Das et al., 2005; Braunwald, 2008; Bhatt et al., 2018). We characterized whether transient or persistent elevations of Nt-proBNP occurred in patients showing a lower BMI at $\mathrm{T} 0$ or a significant decrease of BMI at T1. Patients with normal, transiently high, or persistently high Nt-proBNP presented with a similar BMI at T0 and T1 [25 (20-30), 23 (18-29), $22(19-29)$ at T0; 25 (20-34), 23 (18-32), 24 (17-29) at T1, $P>0.05$ at multiple comparisons]. For each patient group, BMI at T0 correlated linearly with BMI at T1, and correlation slopes were not significantly different from the lines of identity (Fig. 2, upper panels). We next correlated net changes of BMI from T0 to T1 with concomitant net changes of Nt-proBNP levels. We found that: 1) for patients with normal Nt-proBNP, there was a canonical, although borderline, significant inverse correlation between BMI increases and Nt-proBNP decreases (all within the range of normality); 2) for patients with transiently high Nt-proBNP, there was no correlation between Nt-proBNP and BMI; and 3) for patients with persistently high Nt-proBNP,

TABLE 2

Demographic and oncologic characteristics of patients with normal, transiently high, or persistently high Nt-proBNP

\begin{tabular}{|c|c|c|c|c|}
\hline Characteristics & $\begin{array}{c}\text { Normal } \\
(n=28)\end{array}$ & $\begin{array}{l}\text { Transiently high } \\
\qquad(n=27)\end{array}$ & $\begin{array}{l}\text { Persistently high } \\
\qquad(\mathrm{n}=12)\end{array}$ & $\mathbf{P}$ \\
\hline Age (years, median, range) & $47(28-62)$ & $51(31-68)$ & $50(36-60)$ & 0.255 \\
\hline $\begin{array}{c}\text { Gender }(n, \%) \\
\text { male } \\
\text { Female }\end{array}$ & $\begin{array}{c}9(32 \%) \\
19(68 \%)\end{array}$ & $\begin{array}{c}2(7 \%) \\
25(93 \%)^{\star}\end{array}$ & $12(100 \%)^{\star \star}$ & $<0.0001$ \\
\hline $\begin{array}{c}\text { Oncologic disease }(\mathrm{n}, \%) \\
\text { breast cancer } \\
\text { non Hodgkin lymphoma } \\
\text { colorectal cancer }\end{array}$ & $\begin{array}{c}13(46 \%) \\
11(39 \%) \\
4(15 \%)\end{array}$ & $\begin{array}{c}20(74 \%) \\
5(19 \%) \\
2(7 \%)\end{array}$ & $\begin{aligned} 10 & (84 \%) \\
1 & (8 \%) \\
1 & (8 \%)\end{aligned}$ & 0.127 \\
\hline $\begin{array}{l}\text { Chemotherapy ( } \mathrm{n}, \%) \\
\text { anthracycline-based } \\
\text { nonanthracycline }\end{array}$ & $\begin{array}{c}24(86 \%) \\
4(14 \%)\end{array}$ & $\begin{array}{c}25(93 \%) \\
2(7 \%)\end{array}$ & $\begin{array}{c}11(92 \%) \\
1(8 \%)\end{array}$ & 0.682 \\
\hline $\begin{array}{l}\text { Anthracycline dose }{ }^{a)} \\
\left(\mathrm{mg} / \mathrm{m}^{2}, \text { median, range }\right)\end{array}$ & $240(0-317)$ & $240(0-317)$ & $240(0-300)$ & 0.227 \\
\hline
\end{tabular}

Data were analyzed by Kruskal-Wallis one-way analysis of variance with Dunn's post-hoc test or two-tailed Chi-square test or Fisher's exact test, as appropriate. ${ }^{a}$ Expressed as doxorubicin myelotoxic equivalents.

$* P<0.0001$ vs. normal; $* * P<0.0001$ vs. transiently high. 
TABLE 3

Cardiovascular characteristics of patients with normal, transiently high, or persistently high levels of Nt-proBNP

\begin{tabular}{|c|c|c|c|c|}
\hline Parameter & $\begin{array}{c}\text { Normal } \\
(n=28)\end{array}$ & $\begin{array}{l}\text { Transiently high } \\
\qquad(n=27)\end{array}$ & $\begin{array}{l}\text { Persistently high } \\
\qquad(n=12)\end{array}$ & $\mathbf{P}$ \\
\hline $\begin{array}{c}\text { LVEF }(\%) \\
\text { T0 } \\
\text { T1 } \\
\text { P (T0 - T1) }\end{array}$ & $\begin{array}{c}62(55-76) \\
62(55-73) \\
0.917\end{array}$ & $\begin{array}{c}60(55-75) \\
60(52-69) \\
0.983\end{array}$ & $\begin{array}{c}60(50-78) \\
60(55-65) \\
1.000\end{array}$ & $\begin{array}{l}0.120 \\
0.104\end{array}$ \\
\hline $\begin{array}{c}\text { SBP }(\mathrm{mm} \mathrm{Hg}) \\
\text { T0 } \\
\text { T1 } \\
\mathrm{P}(\mathrm{T0}-\mathrm{T} 1)\end{array}$ & $\begin{array}{c}120(100-140) \\
120(100-150) \\
0.961\end{array}$ & $\begin{array}{c}120(90-145) \\
120(100-140) \\
0.614\end{array}$ & $\begin{array}{c}120(100-140) \\
120(105-135) \\
0.519\end{array}$ & $\begin{array}{l}0.899 \\
0.320\end{array}$ \\
\hline $\begin{array}{c}\text { DBP }(\mathrm{mm} \mathrm{Hg}) \\
\text { T0 } \\
\text { T1 } \\
\mathrm{P}(\mathrm{T} 0-\mathrm{T} 1)\end{array}$ & $\begin{array}{c}80(60-90) \\
80(65-90) \\
0.455\end{array}$ & $\begin{array}{c}80(60-85) \\
80(60-90) \\
0.184\end{array}$ & $\begin{array}{c}80(60-85) \\
73(60-85) \\
0.335\end{array}$ & $\begin{array}{l}0.629 \\
0.260\end{array}$ \\
\hline
\end{tabular}

Data were analyzed by Kruskall-Wallis one-way analysis of variance with Dunn's post-hoc test or by Wilcoxon matched paired $t$ test (for T0-T1 differences).

there was an insignificant trend toward a positive correlation between Nt-proBNP elevations and BMI increases (Fig. 2, lower panels). Thus, patients with normal, transiently high, or persistently high Nt-proBNP were balanced for BMI, and changes in the levels of Nt-proBNP showed inconsistent correlations with marginal BMI modifications that occurred in the three groups of patients.

Positive Lusitropic Effect of Nt-proBNP. An impaired diastolic relaxation, defined as grade 1 diastolic dysfunction at echocardiography, was detected in one of 12 patients with
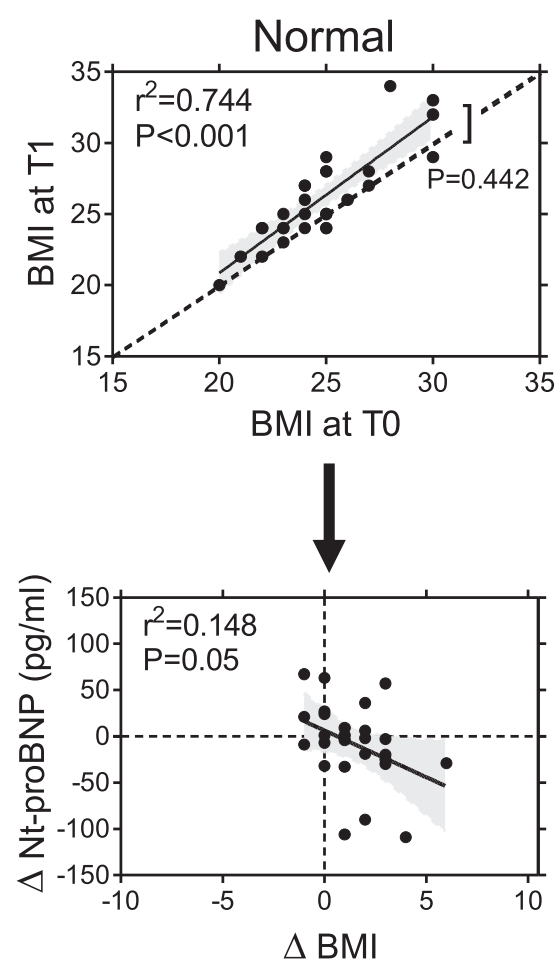
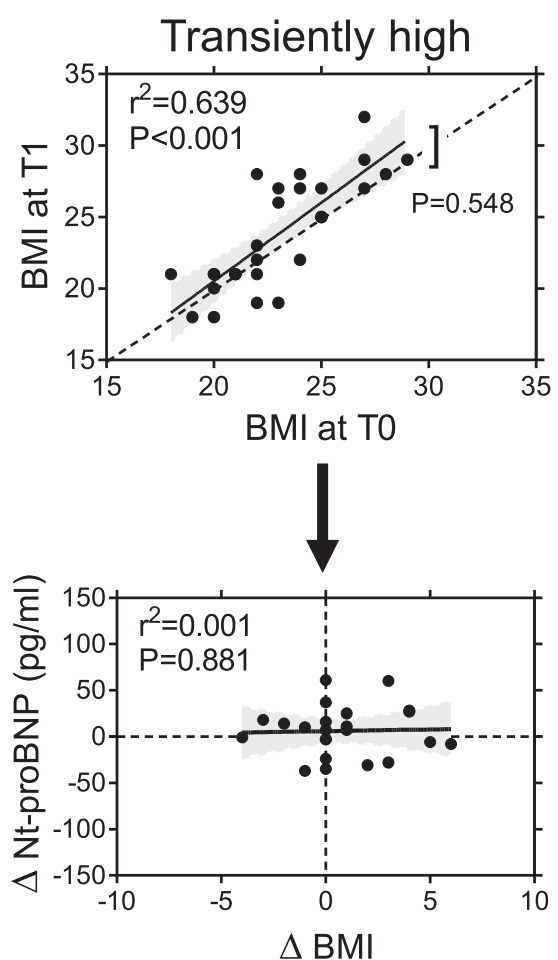
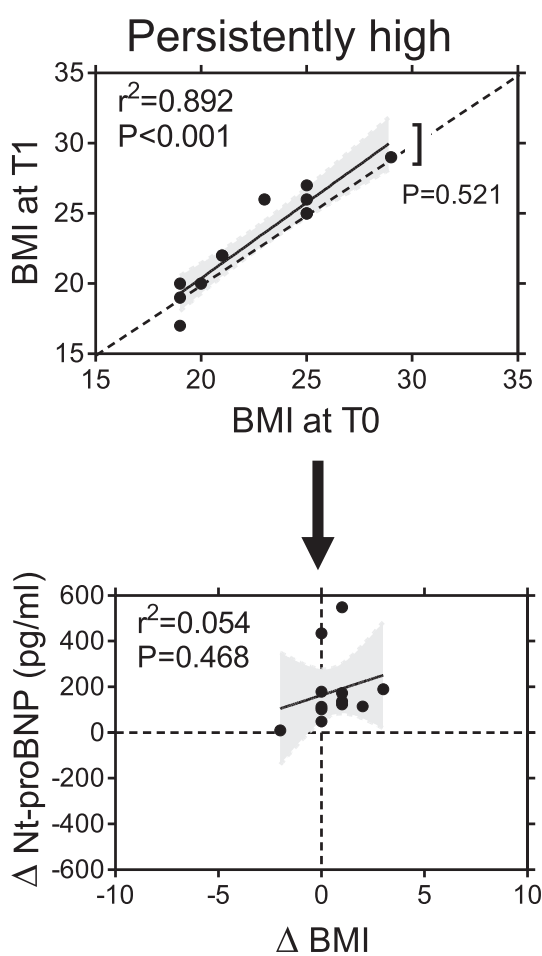

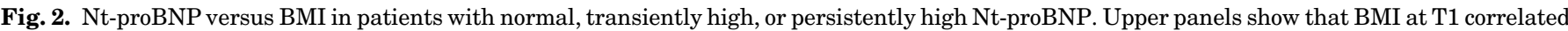

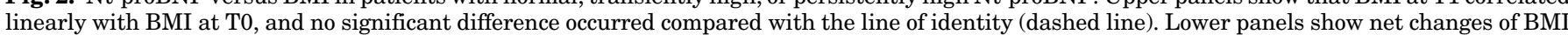

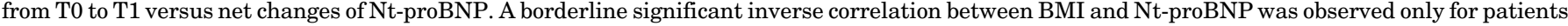
with normal Nt-proBNP. Shaded areas indicate $95 \%$ confidence interval of linear regressions. 
persistently high Nt-proBNP (8\% incidence). Impaired diastolic relaxation was more frequent for patients with normal Nt-proBNP (5/28, 18\% incidence) or transiently high Nt-proBNP (8 of $27,30 \%$ incidence). Of note, impaired relaxation also occurred in two patients treated with nonanthracycline chemotherapy (one normal Nt-proBNP and one transiently high Nt-proBNP). Compared with patients with normal or transiently high Nt-proBNP in aggregate, patients with persistently high Nt-proBNP showed a significantly lower risk of developing an impaired diastolic relaxation $(\mathrm{RR}=0.333,95 \%$ CI $0.16-0.71, P<0.01)$. These findings suggested that high levels of BNP protected against the occurrence of impaired relaxation (positive lusitropic effect).

Some patients received cardiac imaging not only at T0 and T1 but also during chemotherapy. For patients treated by anthracyclines, this usually occurred after a median cumulative dose of $120 \mathrm{mg} / \mathrm{m}^{2}$, which was half the planned median cumulative dose of $240 \mathrm{mg} / \mathrm{m}^{2}$. We therefore explored interactions between a decline in myocardial relaxation and an increase in Nt-proBNP during the course of chemotherapy. Three patterns were observed: 1) for patients with normal Nt-proBNP, the decline in myocardial relaxation occurred unopposed; 2) for patients with transiently high Nt-proBNP, the decline in myocardial relaxation was accompanied by a peak of Nt-proBNP that subsided as relaxation continued worsening and eventually decreased below the range of normality; and 3) for patients with persistently high N-proBNP, the decline in relaxation stopped as Nt-proBNP began to increase. This last pattern occurred regardless of whether patients were given anthracycline-based or nonanthracycline chemotherapy (see Fig. 3 for representative cases). For patients with persistently high Nt-proBNP, LVEF remained unchanged throughout chemotherapy (Fig. 4). Thus, persistent elevations of Nt-proBNP seemed to correlate with a mitigation of impaired relaxation but showed no correlation with LVEF.

We next scrutinized the only patient who presented at T1 with an impaired myocardial relaxation and a concomitant persistent elevation of Nt-proBNP. Compared with 11 other patients with persistently high Nt-proBNP, this patient showed the lowest deviation of Nt-proBNP from the range of normality (Fig. 5A). Myocardial relaxation improved as Nt-proBNP gradually exceeded its range of normality (Fig. 5B).

Positive Chronotropic Effect of High Nt-proBNP. Chemotherapy lowered the Hb count, which was similar for patients with normal, transiently high, or persistently high Nt-proBNP. Hb loss was accompanied by increased HR, which was also similar for the three groups (Table 4). For patients with normal or transiently high Nt-proBNP, increased HR (expressed as $\Delta$ bpm from T0 to T1) correlated with $\mathrm{Hb}$ loss (expressed as $\Delta \mathrm{Hb}$ from $\mathrm{T} 0$ to $\mathrm{T} 1$ ). Patients with persistently high Nt-proBNP did not show such a correlation (Fig. 6, upper panels).

The slope of $\Delta \mathrm{bpm}$ versus $\Delta \mathrm{Hb}$ was identical for patients with normal or transiently high Nt-proBNP $(3.3 \pm 1.3$ vs. $4.2 \pm 1.6$, respectively, $P=0.666)$. A pooled slope of $3.7 \mathrm{bpm} / \mathrm{g}$ of $\mathrm{Hb}$ was therefore obtained and used to calculate theoretical $\Delta \mathrm{bpm}$ (i.e., that $\Delta \mathrm{bpm}$ one would expect to occur at $\mathrm{T} 1$ if all patients gained $3.7 \mathrm{bpm}$ for each gram of $\mathrm{Hb}$ they lost during chemotherapy. Theoretical $\Delta \mathrm{bpm}$ was therefore calculated by
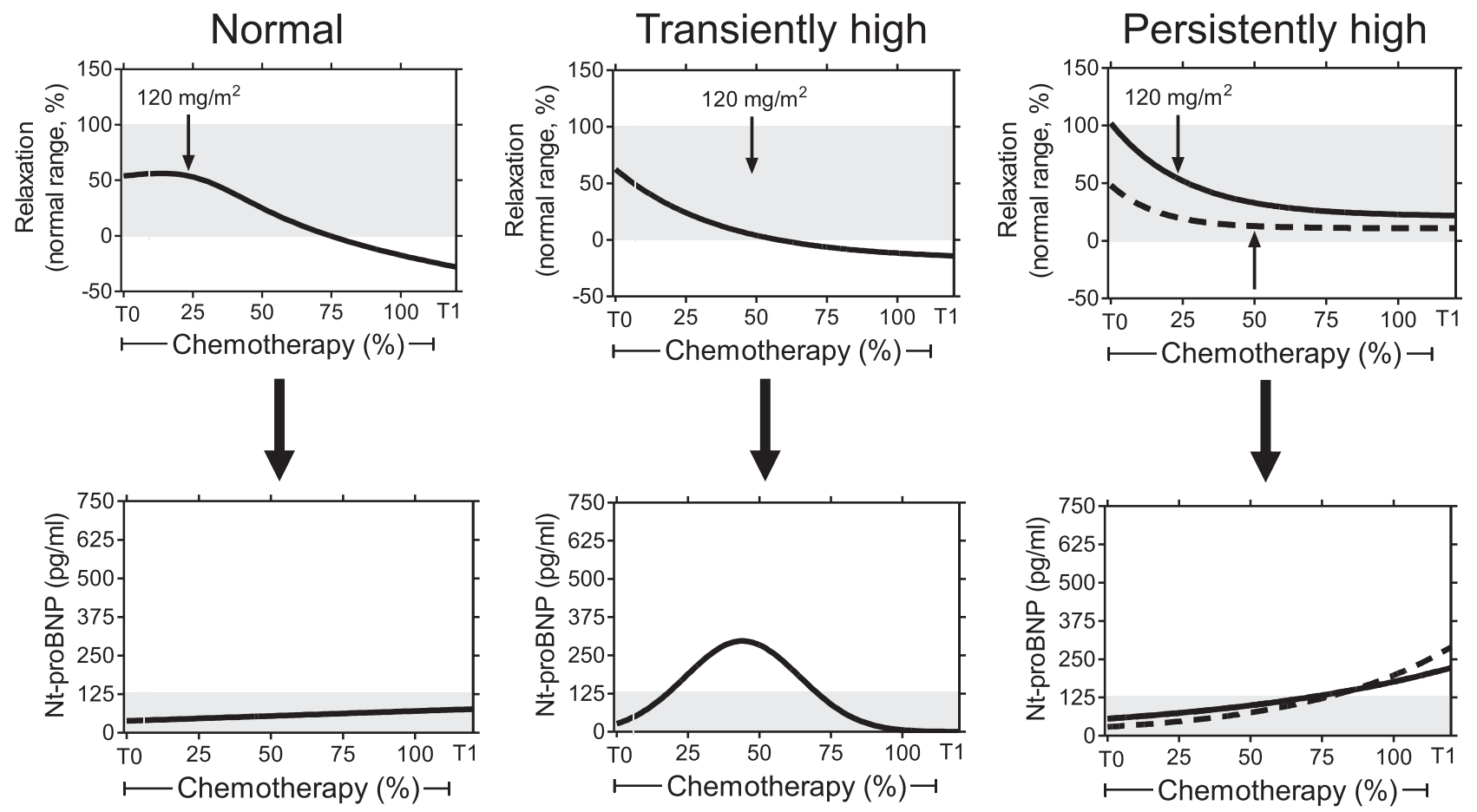

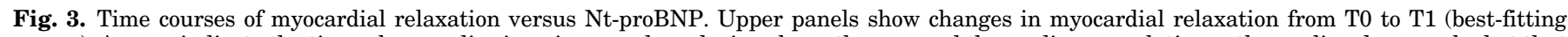

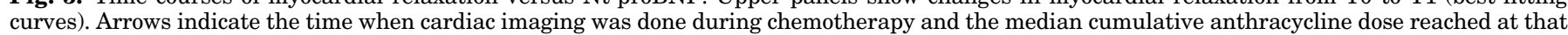

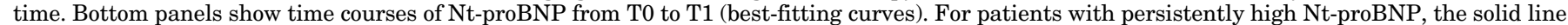

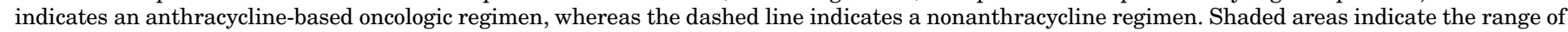

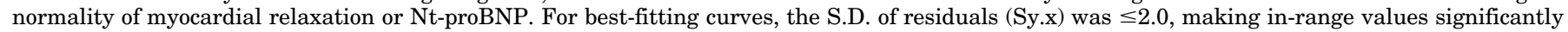
different to out-of-range values. 


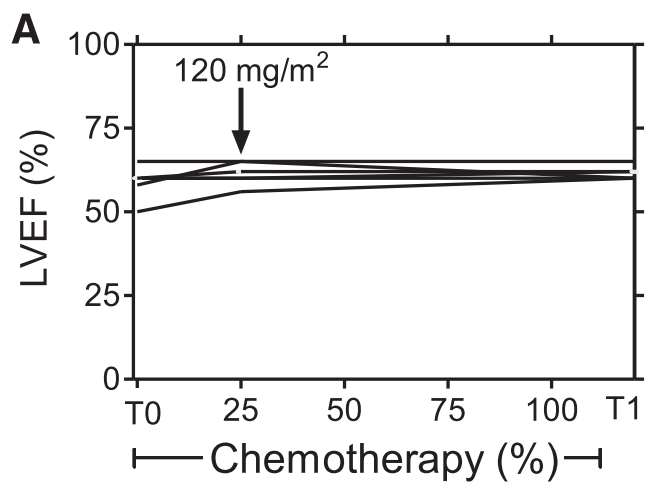

B

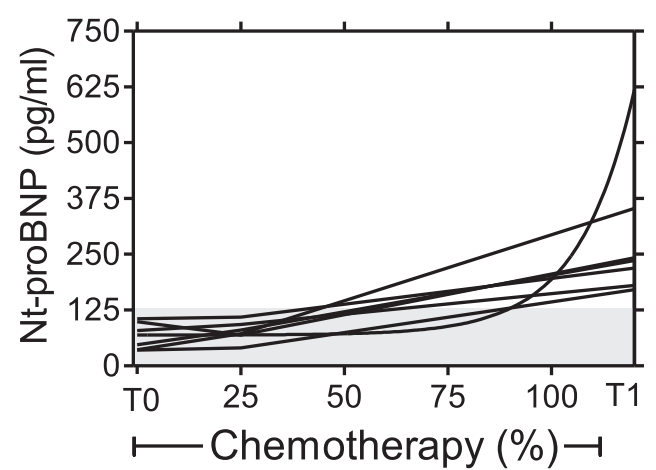

Fig. 4. Time courses of LVEF and Nt-proBNP in patients with persistently high Nt-proBNP. (A) shows LVEF from T0 to T1. Arrows indicate the time when cardiac imaging was done during chemotherapy and the median cumulative anthracycline dose reached at that time. (B) Time course of Nt-proBNP from T0 to T1 (best-fitting curves). The shaded area indicates the range of normality of Nt-proBNP.

the formula $[\Delta \mathrm{bpm}=3.7 \times \Delta \mathrm{Hb}]$. Next, we compared theoretical $\Delta$ bpm with clinical $\Delta$ bpm that was measured by ECG. Theoretical and clinical $\Delta$ bpm levels were eventually plotted against Nt-proBNP levels at T1. For patients with normal or transiently high Nt-proBNP, theoretical $\Delta$ bpm was congruent with clinical $\Delta$ bpm. For patients with persistently high Nt-proBNP, clinical $\Delta$ bpm deviated from and exceeded theoretical $\Delta$ bpm as Nt-proBNP increased above its range of normality (Fig. 6, lower panels), suggesting that persistently high BNP caused an independent effect on increasing HR (positive chronotropic effect).

Effects of a Lusitropic Agent on Myocardial Relaxation, Nt-proBNP, and HR. The antianginal drug ranolazine causes positive lusitropic effects without inducing HR changes (Stone, 2008; Minotti, 2013). Having shown that impaired relaxation and high Nt-proBNP might be mutually exclusive manifestations of diastolic dysfunction, we preliminarily assessed the impact of ranolazine in patients with impaired relaxation/ Nt-proBNP $<125 \mathrm{pg} / \mathrm{ml}(n=6)$ or normal relaxation/persistently high Nt-proBNP $(n=5)$.

After 5 weeks on ranolazine (T5), patients with impaired relaxation and NT-proBNP $<125 \mathrm{pg} / \mathrm{ml}$ (which was either normal or transiently high during chemotherapy) showed a significant improvement in myocardial relaxation, which returned in normal range. In the same patients, ranolazine caused negligible fluctuations of Nt-proBNP, which remained in normal range; moreover, these patients showed an HR decrease that was congruent with the $\mathrm{Hb}$ recovery occurring
A

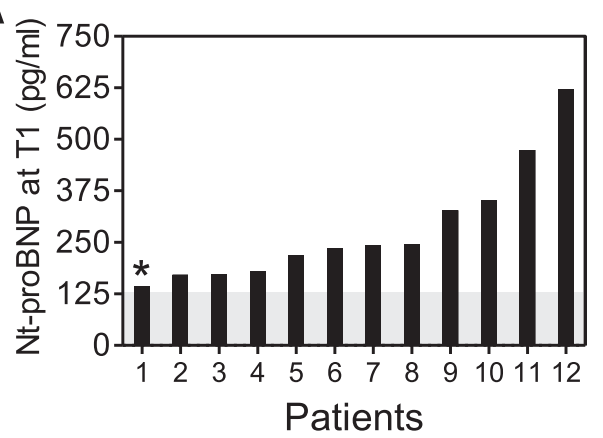

B

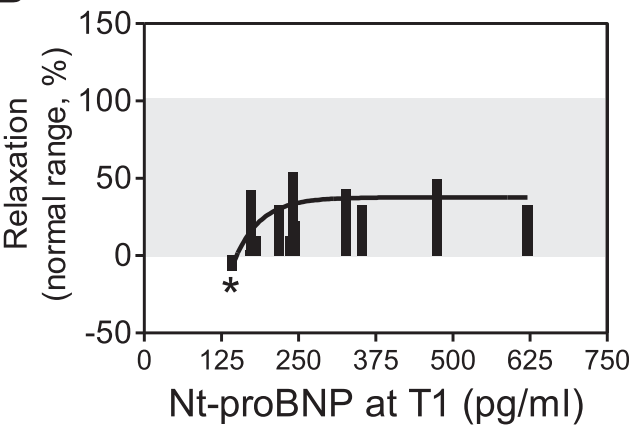

Fig. 5. Nt-proBNP levels and myocardial relaxation in 12 patients with persistently high Nt-proBNP at T1. Panel A shows individual Nt-proBNP levels in 12 patients with persistently high Nt-proBNP at T1. Panel B shows individual values of myocardial relaxation for the same 12 patients (columns and best-fitting curve). *Only patient who developed a persistently high Nt-proBNP and a concomitant impairment of myocardial relaxation. Shaded areas indicate ranges of normality for Nt-proBNP or myocardial relaxation.

from T1 to T5 (i.e., clinical $\Delta$ bpm was not significantly different from theoretical $\Delta \mathrm{bpm}$ calculated by assuming [ $\Delta \mathrm{bpm}=3.7 \times \Delta \mathrm{Hb}]$ ) (Fig. 7, left panels). Thus, for patients with impaired relaxation/ $\mathrm{Nt}$-proBNP $<125 \mathrm{pg} / \mathrm{ml}$, ranolazine exhibited a canonical lusitropic effect.

For patients with normal relaxation and persistently high Nt-proBNP, ranolazine did not cause significant changes in myocardial relaxation, which remained in normal range; interestingly, however, ranolazine caused remarkable decrements of Nt-proBNP. This latter finding suggested that ranolazine, being a lusitropic agent, could substitute for $\mathrm{BNP}$ in preserving diastolic function, and hence it relieved the diastolic distress that stimulated BNP elevations. These patients also exhibited HR decrements that exceeded the effect due to $\mathrm{Hb}$ recovery (i.e., clinical $\Delta$ bpm was significantly higher than theoretical $\Delta \mathrm{bpm}$ ) (Fig. 7, right panels). Having acknowledged that ranolazine per se lacks effects on $\mathrm{HR}$, we considered that $\mathrm{Hb}$-independent $\mathrm{HR}$ decrements were caused by ranolazine through diminishing BNP levels and removing its chronotropic effect.

\section{Discussion}

Dual Effects of BNP Elevations in Cancer Patients with Diastolic Dysfunction. We have shown that chemotherapy-induced BNP elevations may help to mitigate diastolic dysfunction (lusitropic effect); however, this beneficial effect of $\mathrm{BNP}$ comes at the cost of inappropriate 
TABLE 4

Hemoglobin $(\mathrm{Hb})$ and heart rate $(\mathrm{HR})$ in patients with normal, transiently highly, or persistently high Nt-proBNP

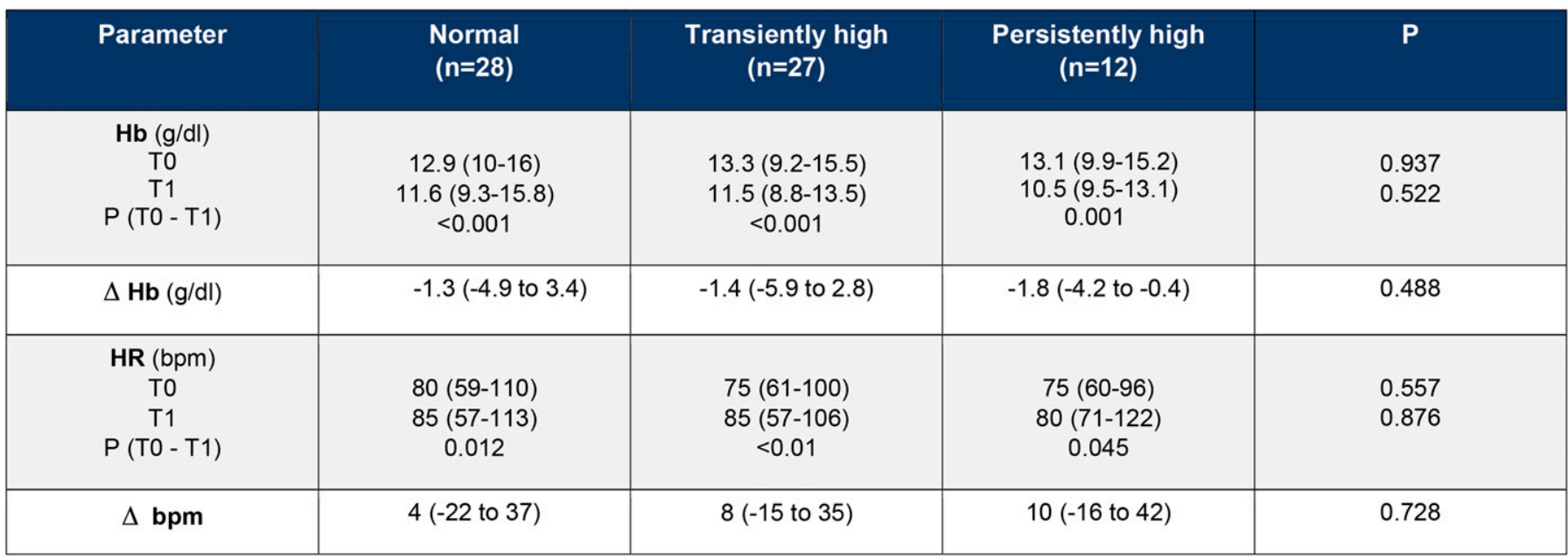

Data were analyzed by Kruskall Wallis one-way analysis of variance with Dunn's post-hoc test or by two-tailed Chi-square test or Wilcoxon matched-paired $t$ test (for T0-T1 differences).

tachycardia that is also caused by high BNP (chronotropic effect) (Fig. 8). These findings shed new light on the role of $\mathrm{BNP}$ in cancer patients.

Evidence and Pharmacologic Foundations for the Lusitropic Effect of BNP in Cancer Patients. The positive lusitropic effect of BNP was inferred from the lower incidence and relative risk of impaired myocardial relaxation in patients with persistently high Nt-proBNP compared with patients with normal or transiently high Nt-proBNP. The time courses of myocardial relaxation versus Nt-proBNP levels were highly suggestive of a sequence of events in which an early decline of relaxation was intercepted and mitigated by persistent BNP elevations before diastolic dysfunction eventually occurred (see Fig. 3). Two lines of evidence also suggest that BNP caused its lusitropic effect in a concentration-dependent manner: 1) positive lusitropy did not occur in a patient showing the lowest deviation of Nt-proBNP from the range of normality; and 2) myocardial relaxation gradually improved as Nt-proBNP exceeded its range of normality (see Fig. 5).
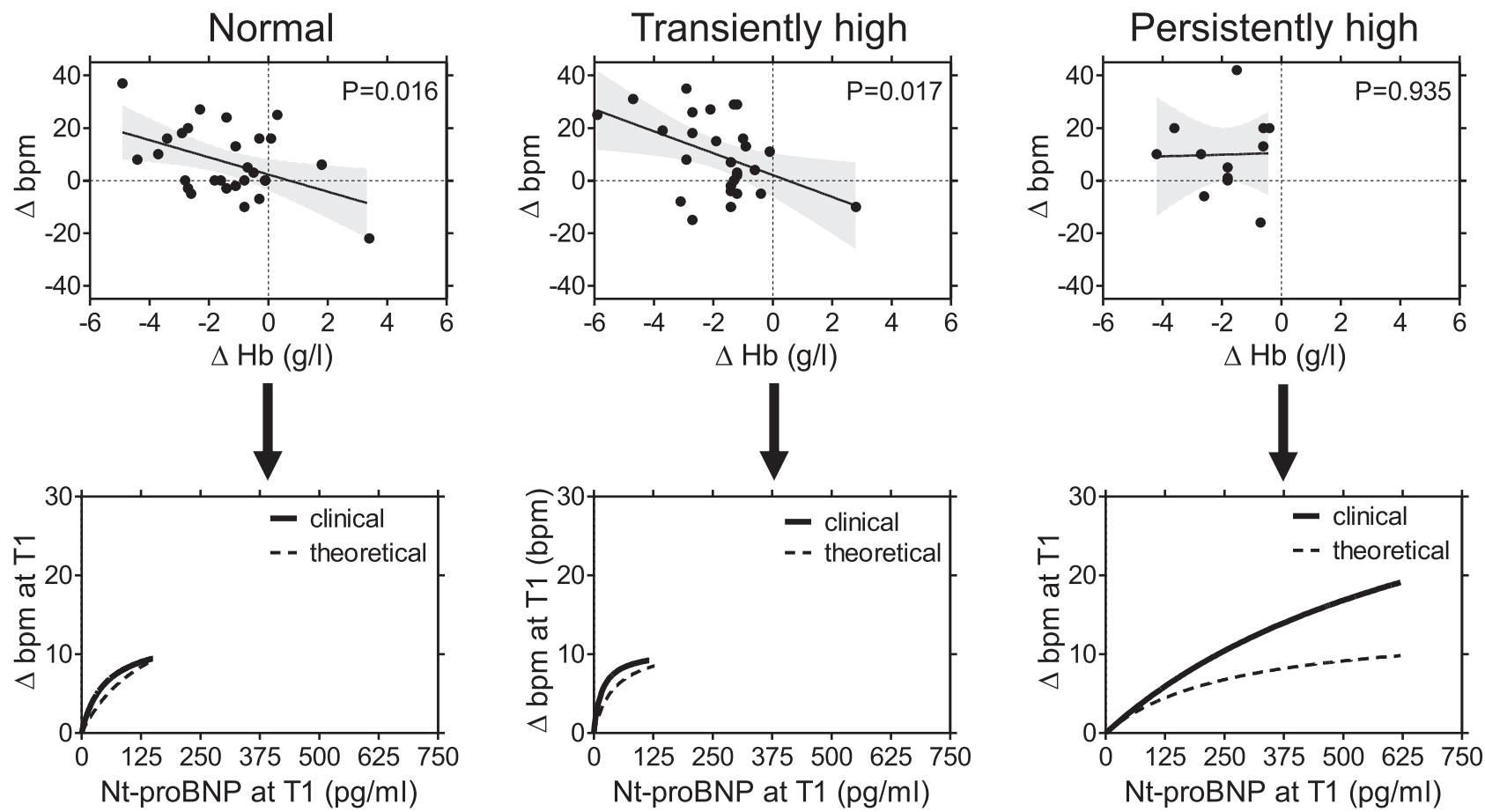

Fig. 6. $\mathrm{Hb}$ loss and $\Delta$ bpm for patients with normal, transiently high, or persistently high Nt-proBNP. Upper panels show that at T1, $\Delta$ bpm correlated with $\Delta \mathrm{Hb}$ for patients with normal or transiently high Nt-proBNP but not for patients with persistently high Nt-proBNP. Shaded areas indicate $95 \%$ confidence intervals of linear regression. Lower panels (best-fitting curves) show that theoretical $\Delta$ bpm was congruent with clinical $\Delta$ bpm for patients with normal or transiently high Nt-proBNP. For patients with persistently high Nt-proBNP, clinical $\Delta$ bpm deviated from and exceeded theoretical $\Delta$ bpm when Nt-proBNP increased above its range of normality. See also text for explanations. 


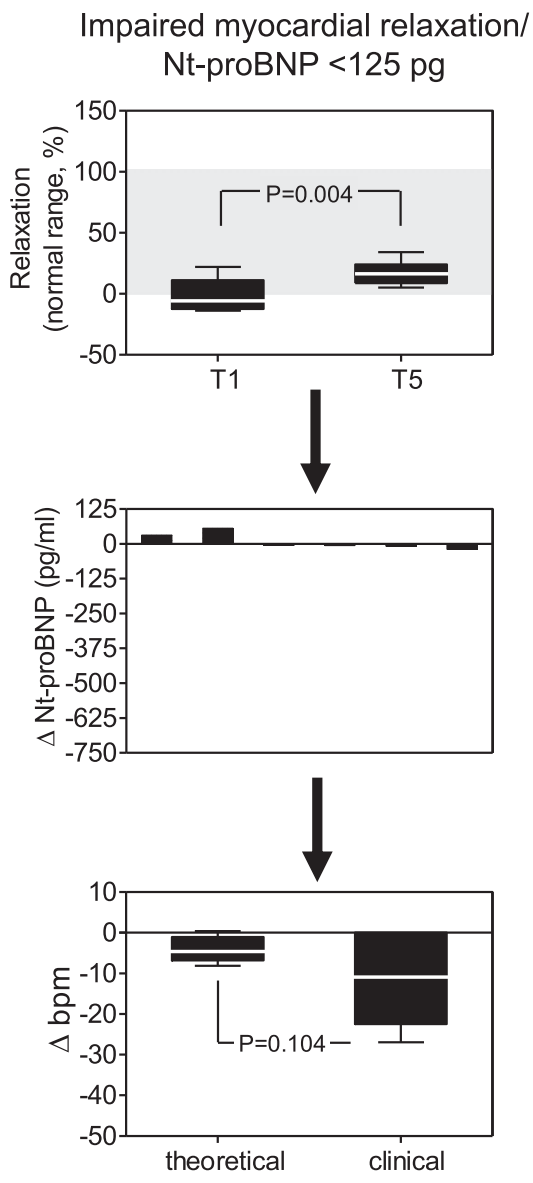

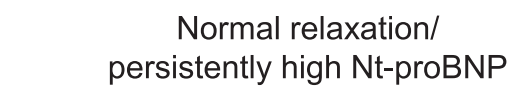
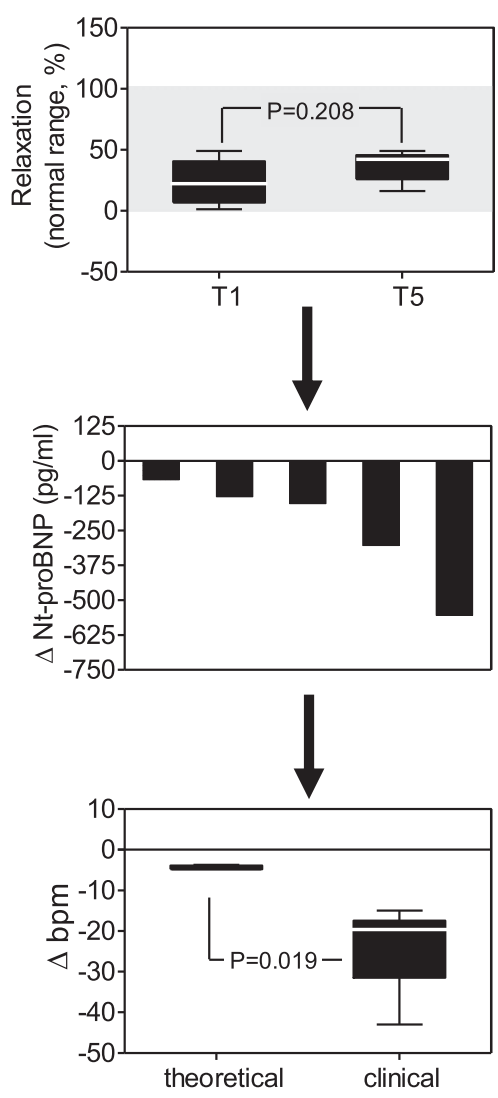

Fig. 7. Effects of 5 weeks of ranolazine on myocardial relaxation, Nt-proBNP, and clinical versus theoretical $\Delta \mathrm{bpm}$ in patients with impaired relaxation/Nt-proBNP $<125 \mathrm{pg} / \mathrm{ml}$ or normal relaxation/persistently high Nt-proBNP. After 5 weeks on ranolazine (T5), patients with impaired relaxation/Nt-proBNP $<125 \mathrm{pg} / \mathrm{ml}$ at T1 (normal or transiently high Nt-proBNP during chemotherapy, $n=6$ ) showed improved myocardial relaxation, insignificant increases or decreases of $\mathrm{Nt}$-proBNP, and a negative clinical $\Delta \mathrm{bpm}$ that was congruent with theoretical $\Delta \mathrm{bpm}$ attributable to $\mathrm{Hb}$ recovery from $\mathrm{T} 1$ to $\mathrm{T} 5(\Delta \mathrm{Hb}=1.3(-0.1$ to 2.2$) \mathrm{g} / \mathrm{dl})$. For patients with normal relaxation/persistently high Nt-proBNP at T1 $(n=5)$, ranolazine did not change myocardial relaxation but diminished Nt-proBNP levels and caused clinical $\Delta \mathrm{bpm}$ that exceeded theoretical $\Delta \mathrm{bpm}$ due to $\mathrm{Hb}$ recovery (median $\Delta \mathrm{Hb}=1.1(1.0-1.3) \mathrm{g} / \mathrm{dl})$.
The pharmacologic foundations of BNP lusitropy may rest with a variety of mechanisms.

Similar to other natriuretic peptides, BNP binds to receptors associated with particulate guanylyl cyclase and cGMP production (Molkentin, 2003; Munagala et al., 2004; Azer et al., 2014). cGMP can then induce relaxant effects through protein kinase $\mathrm{G}$ (PKG)-mediated phosphorylation of titin, which results in a reduced passive tension of cardiomyocytes (Bishu et al., 2011). Evidence for an BNP-dependent phosphorylation of other relaxation-coupled proteins is less solid.

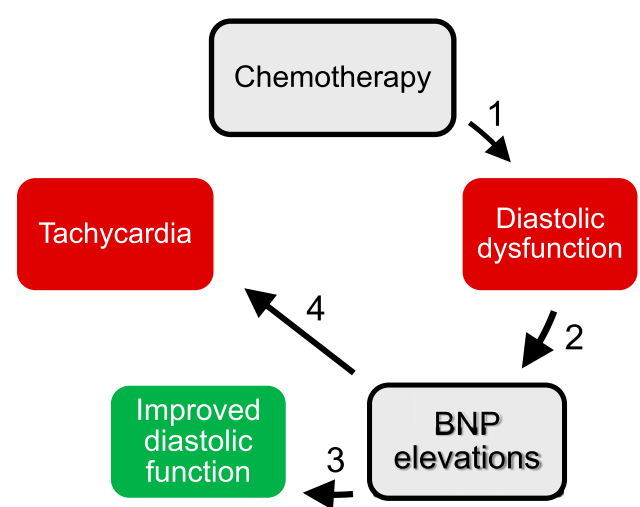

Fig. 8. Schematic representation of the mechanisms and consequences of BNP elevations in cancer patients. Cancer chemotherapy causes diastolic dysfunction (1), which represents a stimulus to BNP elevations (2). High BNP improves diastolic function (3) but causes also an undesired tachycardia (4).
In comparative studies, C-type natriuretic peptide was more effective than BNP in promoting phosphorylation of troponin and phospholamban (Moltzau et al., 2014). Interestingly, however, BNP mobilizes endothelial C-type natriuretic peptide from endothelial cells in humans (Hillock et al., 2008) and measurably increases its lusitropic effect in preclinical models (Moltzau et al., 2014). Beneficial cross-talks between BNP and other natriuretic peptides may therefore occur; accordingly, defects in the BNP-PKG cascade occurred in patients with severe diastolic dysfunction (van Heerebeek et al., 2012).

The BNP-PKG signaling cascade can also promote catecholamine exocytosis from cardiac sympathetic nerve endings, an effect mediated by inhibition of phosphodiesterase type 3-catalyzed hydrolysis of cAMP (Chan et al., 2012). Catecholamine activation of cardiac $\beta_{1}$ or $\beta_{2}$ receptors might then promote concomitant lusitropic and inotropic effects (Molenaar et al., 2007). Here, an adrenergic positive inotropism was not observed; in fact, LVEF did not decrease when chemotherapy was started and did not increase when Nt-proBNP began to rise (see Fig. 4). Involvement of catecholamines cannot therefore be established at this time.

Evidence and Pharmacologic Foundations for the Chronotropic Effect of BNP in Cancer Patients. Myelotoxicity and low $\mathrm{Hb}$ count are common consequences of chemotherapy. Low $\mathrm{Hb}$ count may increase HR through complex reflexes that at least in part originate from carotid body (Lahiri et al., 2006). Here the positive chronotropic effect of BNP was inferred from the following findings: 1) a correlation between $\mathrm{Hb}$ loss and increased $\mathrm{HR}$ occurred for patients with 
normal or transiently high Nt-proBNP but not for patients with persistently high Nt-proBNP; and 2) high Nt-proBNP levels caused $\mathrm{HR}$ to increase independently of $\mathrm{Hb}$ loss (see Fig. 6). Regardless of a possible involvement of exocytosed catecholamines, BNP can increase $\mathrm{HR}$ via receptor-mediated mechanisms. In fact, the binding of $\mathrm{BNP}$ to natriuretic peptide receptor $\mathrm{A}$ increases conduction velocity within the sinoatrial node and toward the surrounding atrial myocardium (Azer et al., 2014). These effects probably involve cGMP activation of L-type $\mathrm{Ca}^{2+}$ current (Springer et al., 2012).

Probing the Role of BNP with Ranolazine. Ranolazine has been approved to treat patients with stable angina, in whom it works by relieving diastolic myocardial tension and by improving coronary conductance. Of note, ranolazine induces its beneficial effects without inducing concomitant changes in SBP, DBP, or HR (Stone, 2008). We described previously the rationale for a phase 2 study in which patients diagnosed at $\mathrm{T} 1$ with diastolic dysfunction were treated with ranolazine. In brief, we suggested that ranolazine, inhibitor of the late inward sodium current, could interrupt vicious cycles that caused $\mathrm{Ca}^{2+}$ overload and impaired relaxation in cardiomyocytes exposed to anthracyclines or nonanthracycline chemotherapeutics (Minotti, 2013). Here, we present preliminary data that recapitulate connections between diastolic relaxation, BNP, and HR. For patients in whom impaired relaxation was not corrected by persistent elevations of $\mathrm{BNP}$, relaxation was improved by the lusitropic effect of ranolazine, whereas $\mathrm{HR}$ decreased in response to an $\mathrm{Hb}$ recovery that occurred over the period of ranolazine administration. For patients in whom diastolic dysfunction was corrected by persistent elevations of $\mathrm{BNP}$, ranolazine relieved the diastolic distress that stimulated BNP elevations; by so doing, ranolazine diminished $\mathrm{BNP}$ levels and caused $\mathrm{HR}$ decrements that reflected an abrogation of the chronotropic effect of BNP. Thus, the effects of a lusitropic drug (ranolazine) were influenced by the levels of an endogenous lusitropic and chronotropic agent (i.e., BNP). Of note, the two lusitropic agents might share some mechanism of action. BNP-driven phosphorylation of relaxation coupled proteins diminishes their sensitivity to $\mathrm{Ca}^{2+}$ (Zhang et al., 1995); in a similar manner, sodium current-independent effects of ranolazine may diminish myofilament sensitivity to $\mathrm{Ca}^{2+}$ (Lovelock et al., 2012).

Study Limitations and Strengths. We acknowledge that our study shows limitations, primarily the relatively limited sample size of these analyses. Moreover, our study cannot elucidate the reason(s) some patients showed a persistently high Nt-proBNP, but others showed normal or only transiently high Nt-proBNP. For the latter patients, the reasons Nt-proBNP failed to remain elevated and to compensate for impaired relaxation call for further investigations. The three patient groups were similar in terms of factors that might have caused differences in prohormone BNP production (age, blood pressure, hormonal status, oncologic regimens). The so-called "BNP diluting effect" of high BMI, provisionally but not unequivocally attributed to a receptor-mediated partitioning of Nt-proBNP or BNP in adipose tissue (Das et al., 2005), has been excluded. Genetic factors governing individual changes in prohormone BNP production and/or BNP or Nt-proBNP pharmacokinetics might be considered (Lanfear et al., 2014). On a different note, we emphasize that all blood samples for Nt-proBNP assays were taken before chemotherapy infusions were started. We therefore exclude confounding factors from fluid overload and cardiomyocyte stretch occurring in some patients but not in others.

Our work shows strengths as well. First, this work modifies and extends our current perception of BNP elevations in cancer patients treated with chemotherapy, showing that $\mathrm{BNP}$ increases in consequence diastolic rather than systolic dysfunction. Second, this work characterizes a potentially beneficial loop in which BNP elevations mitigate diastolic dysfunction. Finally, this work shows that beneficial effects from BNP lusitropy might be counteracted by inappropriate tachycardia caused by BNP chronotropism. BNP should therefore be considered not only as a biomarker but also as a cardiovascular agent with both positive and potentially negative effects. This concept echoes the outcome of a clinical trial in which the administration of recombinant human BNP did not improve net clinical outcomes of patients with acute HF (O'Connor et al., 2011).

From BNP to Pharmacology of Cardio-Oncology. We recently developed translational models of human heart in which $\mathrm{HF}$ risk from anthracyclines was predicted to occur after lower cumulative doses than previously reported and regardless of patient risk factors. This result was attributed to the ease with which anthracyclines accumulate and generate toxic metabolites in human myocardium (Salvatorelli et al., 2017, 2018). Here, we have shown that impaired myocardial relaxation or Nt-proBNP elevations occurred in comorbid free patients treated by a median cumulative anthracycline dose of $240 \mathrm{mg} / \mathrm{m}^{2}$, which was significantly lower than the cumulative dose reported to cause $5 \%$ risk of $\mathrm{HF}$ (400 mg of doxorubicin $/ \mathrm{m}^{2}$ ) (Swain et al., 2003). Myocardial relaxation began to decline after a cumulative anthracycline dose of $120 \mathrm{mg} / \mathrm{m}^{2}$ (see Fig. 3). Clinical pharmacology studies, described in the present study, validate conclusions of basictranslational pharmacology studies. Impaired myocardial relaxation or persistently high Nt-proBNP occurred also in a small group of patients treated by standard doses of nonanthracycline drugs. This last finding supports pharmacologic reasonings that warned against cardiotoxicity from any cancer drug (Minotti et al., 2010).

Monitoring and protecting the cardiac function of cancer patients is important. An early decline in myocardial relaxation should be considered for treatment before diastolic dysfunction progresses toward a more serious stage. BNP or Nt-proBNP elevations should also be considered for treatment as they denote a compensatory mechanism that attempts to mitigate diastolic dysfunction. Inappropriate tachycardia owing to BNP chronotropism represents another reason that patients with high $\mathrm{BNP}$ should receive the adequate treatment to reduce HR. This treatment is not routine currently and requires evidence from ad hoc studies. This will be described in the final report of our phase 2 study of ranolazine versus $\beta$-blockers and other common cardiovascular drugs in cancer patients (Minotti, 2013).

\section{Acknowledgments}

We thank the participants in the pilot study from which data were originated: Giuseppe Avvisati, Daniele Santini, and Giuseppe Tonini (Campus Bio-Medico University, Rome); Claudio Brunelli and Paolo Spallarossa (San Martino Hospital, Genova); Manuela Rizzo and Maria Cantonetti (Tor Vergata University, Rome); Armando Carpino, Alessandra Fabi, and Giuseppe Toglia (IRCCS Regina Elena National Cancer Institute, Rome); Alessandra D’Ambrosi and Francesco Fedele 
(La Sapienza University, Rome); Roberto Fiaschetti and Maria Rita Noviello (Grassi Hospital, Ostia, Rome); Laura Massa (University Hospital, Trieste); Nicola Maurea (National Cancer Institute, Naples); and Stefano Oliva (Giovanni XXXIII Cancer Institute, Bari).

\section{Authorship Contributions}

Participated in research design: Menna, Minotti.

Conducted experiments: Menna, Calabrese, Armento, Annibali, Greco, Marchesi.

Contributed new reagents or analytic tools: Menna.

Performed data analysis: Salvatorelli, Reggiardo, Minotti.

Wrote or contributed to the writing of the manuscript: Minotti.

\section{References}

Azer J, Hua R, Krishnaswamy PS, and Rose RA (2014) Effects of natriuretic peptides on electrical conduction in the sinoatrial node and atrial myocardium of the heart. J Physiol 592:1025-1045.

Bhatt AS, Cooper LB, Ambrosy AP, Clare RM, Coles A, Joyce E, Krishnamoorthy A Butler J, Felker GM, Ezekowitz JA, et al. (2018) Interaction of body mass index on the association between N-terminal-Pro-B-type natriuretic peptide and morbidity and mortality in patients with acute heart failure: findings from ASCEND-HF (acute study of clinical effectiveness of nesiritide in decompensated heart failure). $J$ Am Heart Assoc 7:e006740

Bishu K, Hamdani N, Mohammed SF, Kruger M, Ohtani T, Ogut O, Brozovich FV, Burnett JC, Jr, Linke WA, and Redfield MM (2011) Sildenafil and B-type natriuretic peptide acutely phosphorylate titin and improve diastolic distensibility in vivo. Circulation 124:2882-2891.

Braunwald E (2008) Biomarkers in heart failure N Engl J Med 358:2148-2159.

Calabrese V, Menna P, Annibali O, Armento G, Carpino A, Cerchiara E, Greco C, Marchesi F, Spallarossa P, Toglia G, et al.; Collaborators (2018) Early diastolic dysfunction after cancer chemotherapy: primary endpoint results of a multicenter cardio-oncology study. Chemotherapy 63:55-63.

Carver JR, Shapiro CL, Ng A, Jacobs L, Schwartz C, Virgo KS, Hagerty KL, Somerfield MR, and Vaughn DJ; ASCO Cancer Survivorship Expert Panel (2007) American Society of Clinical Oncology clinical evidence review on the ongoing care of adult cancer survivors: cardiac and pulmonary late effects. $J$ Clin Oncol 25: $3991-4008$.

Chan NY, Seyedi N, Takano K, and Levi R (2012) An unsuspected property of natriuretic peptides: promotion of calcium-dependent catecholamine release via protein kinase G-mediated phosphodiesterase type 3 inhibition. Circulation 125: 298-307.

Daniels LB and Maisel AS (2007) Natriuretic peptides. J Am Coll Cardiol 50: 2357-2368

Das SR, Drazner MH, Dries DL, Vega GL, Stanek HG, Abdullah SM, Canham RM, Chung AK, Leonard D, Wians FH, Jr, et al. (2005) Impact of body mass and body composition on circulating levels of natriuretic peptides: results from the Dallas Heart study. Circulation 112:2163-2168.

European Medicines Agency (2016) Ranexa: Summary of product characteristics, pp $1-61$.

Ewer MS (2013) Anthracycline cardiotoxicity: clinical aspects, recognition, monitoring, treatment, and prevention, in Cancer and the Heart (Ewer MS and Yeh ET, eds) pp 11-41, People's Medical Publishing House, Shelton, CT.

Ewer MS and Lenihan DJ (2008) Left ventricular ejection fraction and cardiotoxicity: is our ear really to the ground? J Clin Oncol 26:1201-1203.

Hillock RJ, Frampton CM, Yandle TG, Troughton RW, Lainchbury JG, and Richards AM (2008) B-type natriuretic peptide infusions in acute myocardial infarction. Heart 94:617-622.

Lahiri S, Roy A, Baby SM, Hoshi T, Semenza GL, and Prabhakar NR (2006) Oxygen sensing in the body. Prog Biophys Mol Biol 91:249-286.

Lanfear DE, Chow S, Padhukasahasram B, Li J, Langholz D, Tang WH, Williams LK, and Sabbah HN (2014) Genetic and nongenetic factors influencing pharmacokinetics of B-type natriuretic peptide. J Card Fail 20:662-668.

Lovelock JD, Monasky MM, Jeong EM, Lardin HA, Liu H, Patel BG, Taglieri DM, Gu L, Kumar P, Pokhrel N, et al. (2012) Ranolazine improves cardiac diastolic dysfunction through modulation of myofilament calcium sensitivity. Circ Res 110 $841-850$.

Lukowicz TV, Fischer M, Hense HW, Döring A, Stritzke J, Riegger G, Schunkert H, and Luchner A; MONICA Investigators (2005) BNP as a marker of diastolic dysfunction in the general population: Importance of left ventricular hypertrophy. Eur $J$ Heart Fail 7:525-531.

Masson S, Latini R, Anand IS, Vago T, Angelici L, Barlera S, Missov ED, Clerico A Tognoni G, and Cohn JN; Val-HeFT Investigators (2006) Direct comparison of B-type natriuretic peptide (BNP) and amino-terminal proBNP in a large population of patients with chronic and symptomatic heart failure: the Valsartan heart failure (Val-HeFT) data. Clin Chem 52:1528-1538.

Menna P and Salvatorelli E (2017) Primary prevention strategies for anthracycline cardiotoxicity: a brief overview. Chemotherapy 62:159-168.
Menna P, Salvatorelli E, and Minotti G (2008) Cardiotoxicity of antitumor drugs. Chem Res Toxicol 21:978-989.

Minotti G (2013) Pharmacology at work for cardio-oncology: ranolazine to treat early cardiotoxicity induced by antitumor drugs. J Pharmacol Exp Ther 346: $343-349$.

Minotti G, Menna P, Salvatorelli E, Cairo G, and Gianni L (2004) Anthracyclines: molecular advances and pharmacologic developments in antitumor activity and cardiotoxicity. Pharmacol Rev 56:185-229.

Minotti G, Salvatorelli E, and Menna P (2010) Pharmacological foundations of cardiooncology. J Pharmacol Exp Ther 334:2-8.

Molenaar P, Savarimuthu SM, Sarsero D, Chen L, Semmler AB, Carle A, Yang I, Bartel S, Vetter D, Beyerdörfer I, et al. (2007) (-)-Adrenaline elicits positive inotropic, lusitropic, and biochemical effects through beta2 -adrenoceptors in human atrial myocardium from nonfailing and failing hearts, consistent with Gs coupling but not with Gi coupling. Naunyn Schmiedebergs Arch Pharmacol 375:11-28.

Molkentin JD (2003) A friend within the heart: natriuretic peptide receptor signaling. J Clin Invest 111:1275-1277.

Moltzau LR, Aronsen JM, Meier S, Skogestad J, Ørstavik Ø, Lothe GB, Sjaastad I, Skomedal T, Osnes JB, Levy FO, et al. (2014) Different compartmentation of responses to brain natriuretic peptide and C-type natriuretic peptide in failing rat ventricle. J Pharmacol Exp Ther 350:681-690.

Munagala VK, Burnett JC, Jr, and Redfield MM (2004) The natriuretic peptides in cardiovascular medicine. Curr Probl Cardiol 29:707-769.

O'Connor CM, Starling RC, Hernandez AF, Armstrong PW, Dickstein K, Hasselblad V, Heizer GM, Komajda M, Massie BM, McMurray JJ, et al. (2011) Effect of nesiritide in patients with acute decompensated heart failure [published correction appears in $N$ Engl J Med (2011) 365:773]. N Engl J Med 365:32-43.

Omland T, Sabatine MS, Jablonski KA, Rice MM, Hsia J, Wergeland R, Landaas S, Rouleau JL, Domanski MJ, Hall C, et al.; PEACE Investigators (2007) Prognostic value of B-Type natriuretic peptides in patients with stable coronary artery disease: the PEACE trial. $J$ Am Coll Cardiol 50:205-214.

Politi P, Minoretti P, Piaggi N, Brondino N, and Emanuele E (2007) Elevated plasma N-terminal ProBNP levels in unmedicated patients with major depressive disorder. Neurosci Lett 417:322-325.

Previtali M, Chieffo E, Ferrario M, and Klersy C (2012) Is mitral E/E' ratio a reliable predictor of left ventricular diastolic pressures in patients without heart failure? Eur Heart J Cardiovasc Imaging 13:588-595.

Romano S, Fratini S, Ricevuto E, Procaccini V, Stifano G, Mancini M, Di Mauro M, Ficorella C, and Penco M (2011) Serial measurements of NT-proBNP are predictive of not-high-dose anthracycline cardiotoxicity in breast cancer patients. $\mathrm{Br} J \mathrm{Cancer}$ 105:1663-1668.

Salvatorelli E, Menna P, Chello M, Covino E, and Minotti G (2017) Modeling human myocardium exposure to doxorubicin defines the risk of heart failure from low-dose doxorubicin. J Pharmacol Exp Ther 362:263-270.

Salvatorelli E, Menna P, Chello M, Covino E, and Minotti G (2018) Low-dose anthracycline and risk of heart failure in a pharmacokinetic model of human myocardium exposure: analog specificity and role of secondary alcohol metabolites. $J$ Pharmacol Exp Ther 364:323-331.

Siemens Technical Note (2012) Dimension Vista ${ }^{\circledR}$ PBNP datasheet, updated information from 2012-10 Siemens Healthcare GmbH, Erlangen, Germany.

Springer J, Azer J, Hua R, Robbins C, Adamczyk A, McBoyle S, Bissell MB, and Rose RA (2012) The natriuretic peptides BNP and CNP increase heart rate and electrical conduction by stimulating ionic currents in the sinoatrial node and atria myocardium following activation of guanylyl cyclase-linked natriuretic peptide receptors. J Mol Cell Cardiol 52:1122-1134.

Stone PH (2008) Ranolazine: new paradigm for management of myocardial ischemia, myocardial dysfunction, and arrhythmias. Cardiol Clin 26:603-614.

Swain SM, Whaley FS, and Ewer MS (2003) Congestive heart failure in patients treated with doxorubicin: a retrospective analysis of three trials. Cancer 97: 2869-2879.

van Heerebeek L, Hamdani N, Falcão-Pires I, Leite-Moreira AF, Begieneman MP Bronzwaer JG, van der Velden J, Stienen GJ, Laarman GJ, Somsen A, et al. (2012) Low myocardial protein kinase $\mathrm{G}$ activity in heart failure with preserved ejection fraction. Circulation 126:830-839.

Vejpongsa P and Yeh ET (2014) Prevention of anthracycline-induced cardiotoxicity: challenges and opportunities. J Am Coll Cardiol 64:938-945.

Weber M and Hamm C (2006) Role of B-type natriuretic peptide (BNP) and NT-proBNP in clinical routine. Heart 92:843-849.

Zamorano JL, Lancellotti P, Rodriguez Muñoz D, Aboyans V, Asteggiano R, Galderisi M, Habib G, Lenihan DJ, Lip GYH, Lyon AR, et al.; ESC Scientific Document Group (2016) ESC Position paper on cancer treatments and cardiovascular toxicity developed under the auspices of the ESC Committee for Practice Guidelines: The Task Force for cancer treatments and cardiovascular toxicity of the European Society of Cardiology (ESC). Eur Heart $J$ 37:2768-2801.

Zhang R, Zhao J, Mandveno A, and Potter JD (1995) Cardiac troponin I phosphorylation increases the rate of cardiac muscle relaxation. Circ Res 76:1028-1035.

Address correspondence to: Giorgio Minotti, Department of Medicine, University Campus Bio-Medico, Via Alvaro del Portillo, 21, 00128 Rome, Italy. E-mail: g.minotti@unicampus.it 